\section{Negative Predictive Value of Ultrasound in Evaluation of Malignancy in Hypofunction- ing Thyroid Nodules}

\author{
Kim Xia*, Abigail Chong, Geoffrey Soo, lan Jong, Shakher \\ Ramdave, Paul Bowen and Deepali Nandurkar
}

Diagnostic Imaging, Monash Medical Centre, Australia

\begin{abstract}
Introduction

A solid hypofunctioning (cold) nodule on scintigraphy is associated with an increased risk of malignancy while a functioning (hot) nodule is rarely malignant. This study aims to assess if we can avoid invasive investigation of cold thyroid nodules by risk stratifying using ultrasound.

\section{Methods}

This study is a retrospective audit correlating the sonographic and cytological findings of solid hypofunctioning nodules on Tc-99m pertechnetate scintigraphy. The sonographic features and cytology for benign and malignant nodules were compared using Fisher's exact test and the unpaired T-test. A $P$ value $<0.05$ was considered statistically significant.

Results

A total of 67 cold nodules were examined. Fourteen nodules were excluded due to indeterminate cytology and non-diagnostic fine needle aspiration. In the resulting sample of 53 nodules, 21 nodules demonstrated suspicious features on ultrasound and 32 nodules had no suspicious ultrasound findings. Absence of suspicious sonographic features on ultrasound has a high negative predictive value of $0.94(95 \% \mathrm{Cl} 0.79-0.99)$, but presence of suspicious sonographic features has a poor positive predictive value of $0.14(95 \% \mathrm{Cl} 0.03-0.36)$ for cold nodules. There was a strong correlation between nodule echogenicity and cytology $(P=0.02)$. The absence of marked hypoechogencity had a high negative predictive value of $0.96(95 \% \mathrm{Cl} 0.85-0.99)$, but poor positive predictive value of 0.38 (95\% $\mathrm{Cl} 0.085-0.76)$.

\section{Conclusion}

There was a statistically significant association between absence of suspicious sonographic findings and benign cytology in our study.
\end{abstract}

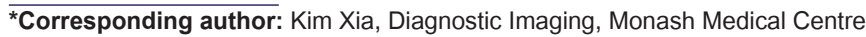
246 Clayton Rd, Clayton VIC 3168, Australia, Tel: +61 0247342613; Email: kimjxia@gmail.com

Citation: Xia K, Chong A, Soo G, Jong I, Ramdave S, et al. (2016) Negative Predictive Value of Ultrasound in Evaluation of Malignancy in Hypofunctioning Thyroid Nodules. J Hum Endocrinol 1: 004.

Received: May 17, 2016; Accepted: June 30, 2016; Published: July 14, 2016

Copyright: (c) 2016 Xia K, et al., This is an open-access article distributed under the terms of the Creative Commons Attribution License, which permits unrestricted use, distribution, and reproduction in any medium, provided the original author and source are credited.
This suggests that ultrasound can be used to stratify a cold thyroid nodule before invasive procedures are performed.

Keywords: Cold nodule; Fine needle aspirate; Hypofunctioning nodule; Malignant cytology; Ultrasound

\section{Introduction}

Thyroid nodules are common in the general population. Of randomly selected individuals in an iodine sufficient population, 19-67\% will have incidentally detected nodules when evaluated with high frequency ultrasound [1] and thyroid nodules have been found in fifty percent of autopsy specimens in the United States [2]. The risk of malignancy in a thyroid nodule is influenced by the patient's age, sex, radiation exposure and family history but overall has an incidence of approximately $5 \%[3-6]$.

A solid hypofunctioning (cold) nodule on scintigraphy is associated with an increased risk of malignancy while a functioning (hot) nodule is rarely malignant $[7,8]$. An American study by Kountakis et al., demonstrated $27.5 \%$ of a population of 189 cold nodules to be malignant [9]. Traditionally, these nodules are referred for cytological sampling via fine needle aspirate for evaluation of malignancy. Noninvasive imaging modalities, in particular high frequency ultrasound has been used to stratify the risk of malignancy and target nodules which require further cytological sampling however limited studies have investigated the use of ultrasound specifically in the cold nodule population. Suspicious sonographic features include irregular margins, the presence of microcalcifications, increased vascularity, being taller than wide and marked hypoechogenicity compared with the infrahyoid muscle [10]. Traditionally nodules larger than $1 \mathrm{~cm}$ are subject to biopsy as studies have demonstrated increased morbidity and inadequate samples for Fine Needle Aspirate (FNA) sampling of subcentimeter nodules and the likelihood that treatment of microcarcinomas does not improve life expectancy $[6,11,12]$.

A European study by Rago et al., in 1998 sought to examine the usefulness of thyroid ultrasound and colour Doppler sonography in cold nodules. This study found a high positive predictive value of positive sonographic findings only when at least 2 signs were present within a 'cold' thyroid nodule with a specificity of up to $93.2 \%$ but relatively low sensitivity of $26.6 \%$ [13]. Since this study, there have not been any studies evaluating the combination of scintigraphic and sonographic findings on modern scanners to stratify malignancy risk in this population.

This study assesses if the risk of malignancy in patients with cold nodules can be stratified according to the presence of sonographic features and therefore determines the need for invasive cytopathological correlation.

\section{Materials and Methods}

This study is a retrospective audit correlating the sonographic and cytological findings of solid hypofunctioning nodules on Tc-99m pertechnetate scintigraphy. It was performed in compliance with our institutional research guidelines.

Patients with hypofunctioning nodules on scintigraphy carried out at our institution between January 2005 and February 2015 were 
identified using the hospital's picture archiving and communications system search engine. Those who had all follow up imaging and pathology results within the Monash Health network were included in the study.

Nodules with a solid component detected on ultrasound were included in the study. All nodules were larger than $1 \mathrm{~cm}$ given the resolution of pertechnetate scintigraphy in initial detection and selection into the study. The presence or absence of specific sonographic features [marked hypoechogenicity (lower when compared with the infrahyoid musculature), irregular margins, microcalcifications, hypervascularity and taller than wide] was established for each nodule. These findings were correlated with fine needle aspirate cytology results which were classified into two categories, benign cytology (hyperplastic nodule and colloid nodule) or malignant cytology (features of carcinoma). Patients with non-diagnostic or indeterminate cytology results were excluded.

Scintigraphic assessment was performed on Philips Skylight, Philips CardioMD, Philips Precedence, GE Discovery 670 and ADAC Forte.

Sonographic assessment was performed on Philip ATL 5000, Philips IU22 and GE Logiq 9. Linear 6-15 and 5-9 transducers were used. Transverse and longitudinal images and colour Doppler images were routinely obtained by qualified sonographers.

Cytological assessment was performed using fine needle aspirate which were routinely performed with a pathologist or pathology technician on site to confirm adequate samples were obtained.

The sonographic features and cytology for benign and malignant nodules were compared using fisher's exact test and the unpaired T-test. A $P$ value $<0.05$ was considered statistically significant.

\section{Results}

A total of 67 cold nodules were examined. Fourteen nodules were excluded due to indeterminate cytology (7/67) and non-diagnostic fine needle aspiration (7/67). Of the remaining 53 nodules, 21 nodules demonstrated suspicious features on ultrasound and 32 nodules had no suspicious ultrasound findings (Figure 1). The majority of the indications for scintigraphy were for investigation of the cause of hyperthyroidism with the detection of a cold nodule being an incidental finding.

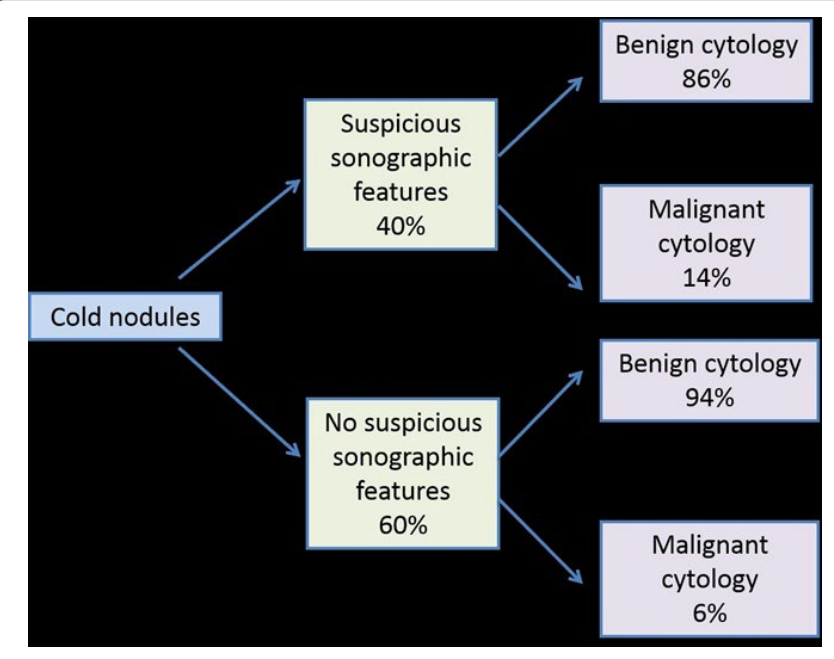

Figure 1: Pathological and sonographic classification of cold nodules.
Absence of suspicious sonographic features on ultrasound has a high negative predictive value of 0.94 (95\% CI 0.79-0.99), but presence of suspicious sonographic features has a poor positive predictive value of 0.14 (95\% CI $0.03-0.36$ ) for cold nodules. Of the 32 nodules with no suspicious ultrasound findings, 30 nodules $(30 / 32=93.8 \%)$ were benign and two $(2 / 32=6.2 \%)$ had malignant cytology (papillary carcinoma and follicular with micropapillary carcinoma $(P<0.0001)$. Of the 21 nodules with suspicious ultrasound features, three malignancies $(3 / 21=14.3 \%)$ were detected on cytology (one follicular and two papillary thyroid carcinomas), with the remaining 18 nodules $(18 / 21=85.7 \%)$ having benign cytology (Figure 2). Of the three nodules which were malignant, all were markedly hypoechoic. Two of the three had increased vascularity and one had irregular margins (Figures 3 and 4).

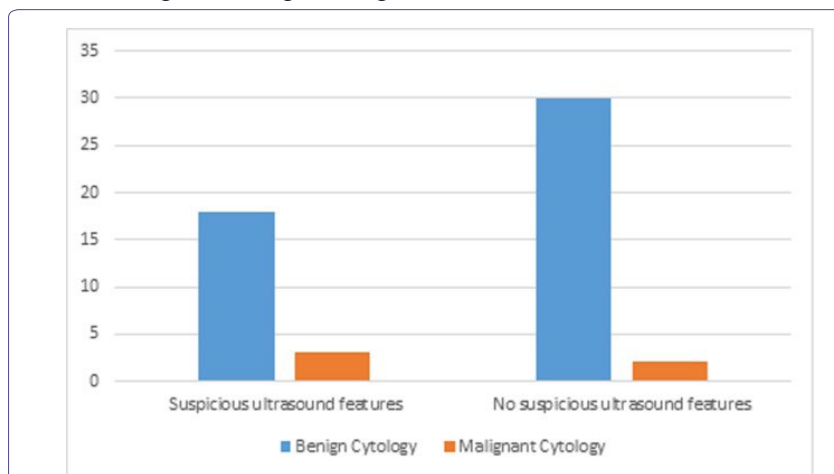

Figure 2: Correlation between ultrasound and cytological assessment of cold nodules.

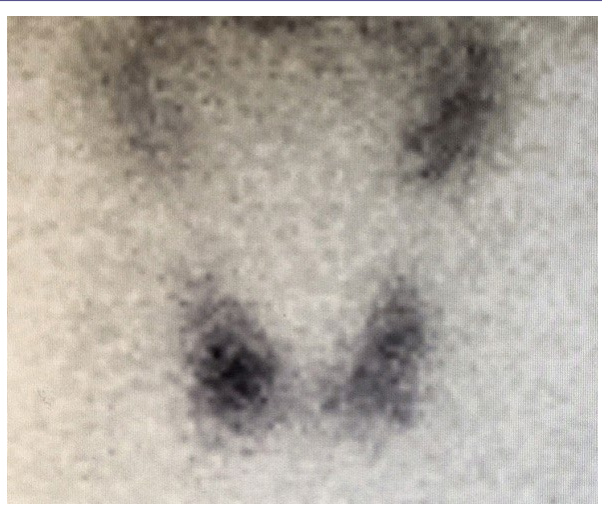

Figure 3: Technetium pertechnetate study demonstrated cold nodule in the inferior pole of the left lobe of the thyroid.

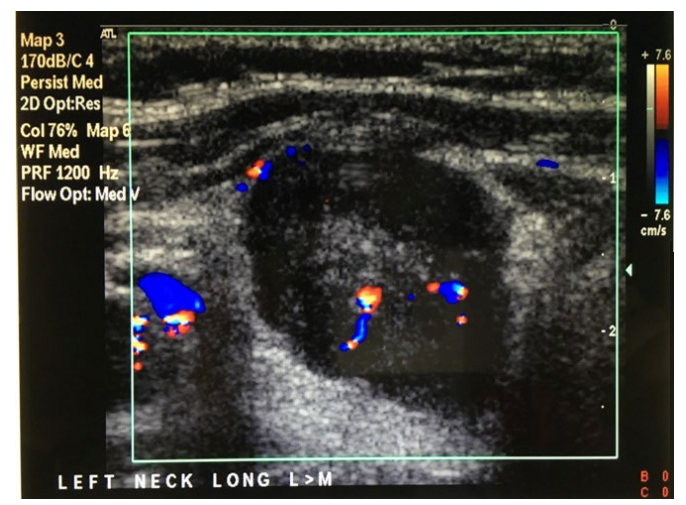

Figure 4: Doppler ultrasound demonstrating a markedly hypoechoic lesion in the left lower. 
There was a strong correlation between nodule echogenicity and cytology $(P=0.02)$, with 43 nodules without marked hypoechogenicity $(43 / 53=81.1 \%)$ having benign cytology and 3 markedly hypoechoic nodules $(3 / 53=5.7 \%)$ having malignant cytology. Five nodules with marked hypoechoic appearance $(5 / 53=9.4 \%)$ had benign cytology, and two nodules without marked hypoechoic appearance $(2 / 53=3.8 \%)$ were malignant. The absence of marked hypoechogencity had a high negative predictive value of 0.96 (95\% CI $0.85-0.99$ ), but poor positive predictive value of 0.38 (95\% CI $0.085-0.76)$. No statistically significant correlation was found between other sonographic features and cytology (Table 1). higher accuracy of ultrasound in this context. This has important clinical implications as there is an argument to be made against subjecting patients with cold nodules but that have no suspicious sonographic features to an invasive test.

Our study demonstrated a strong correlation between marked hypoechogenicity (Figure 3 ) and malignant cytology with a sensitivity of $60 \%$ and specificity of $90 \%(P=0.02)$. This is comparable to multicenter data from Moon et al., [17] demonstrating the sensitivity of $41.4 \%$ and specificity of $92.2 \%(p<0.05)$ for marked hypoechogenicity as a sonographic feature of malignancy. No statistically significant

\begin{tabular}{|c|c|c|c|c|c|c|}
\hline $\begin{array}{l}\text { Ultrasound features } \\
\text { vs cytology }\end{array}$ & $\begin{array}{l}\text { P value } \\
(P<0.05)\end{array}$ & $\begin{array}{c}\text { Sensitivity (95\% } \\
\text { Confidence } \\
\text { interval) }\end{array}$ & $\begin{array}{l}\text { Specificity }(95 \% \\
\text { confidence } \\
\text { interval) }\end{array}$ & $\begin{array}{c}\text { Positive } \\
\text { predictive value }\end{array}$ & $\begin{array}{c}\text { Negative } \\
\text { predictive value }\end{array}$ & $\begin{array}{l}\text { Likelihood } \\
\quad \text { ratio }\end{array}$ \\
\hline $\begin{array}{l}\text { Overall suspicious } \\
\text { ultrasound findings }\end{array}$ & 0.3 & $0.60(0.15-0.95)$ & $0.63(0.47-0.76)$ & $0.14(0.03-0.36)$ & $0.94(0.79-0.99)$ & 1.6 \\
\hline Hypoechoic & $0.02 *$ & $0.60(0.15-0.95)$ & $0.90(0.77-0.97)$ & $0.38(0.085-0.76)$ & $0.96(0.85-0.99)$ & 5.8 \\
\hline $\begin{array}{l}\text { Increased vascu- } \\
\text { larity }\end{array}$ & 0.12 & $0.40(0.053-0.85)$ & $0.90(0.77-0.97)$ & $0.29(0.037-0.71)$ & $0.93(0.82-0.99)$ & 3.8 \\
\hline $\begin{array}{l}\text { Irregular margins } \\
\text { vs Cytology }\end{array}$ & 0.66 & $0.0(0.0-0.52)$ & $0.92(0.80-0.98)$ & $0.0(0.0-0.60)$ & $0.90(0.78-0.97)$ & 0.0 \\
\hline Microcalcification & 0.48 & $0.0(0.0-0.52)$ & $0.85(0.72-0.94)$ & $0.0(0.0-0.41)$ & $0.89(0.76-0.96)$ & 0.0 \\
\hline Taller than wide & 0.74 & $0.0(0.0-0.52)$ & $0.94(0.83-0.99)$ & $0.0(0.0-0.71)$ & $0.90(0.78-0.97)$ & 0.0 \\
\hline $\begin{array}{l}\text { Overall non-suspi- } \\
\text { cious US findings }\end{array}$ & $<0.0001$ & & & & & \\
\hline
\end{tabular}

Table 1: Sensitivity, specificity, positive predictive value and negative predictive value of ultrasound findings.

\section{Discussion}

Management and surveillance of thyroid nodules poses a common clinical scenario given the high prevalence of nodules in the population. Cold nodules on scintigraphy have traditionally been considered an increased risk for malignancy however ultrasound has also become a well established mode of risk stratification of thyroid nodules.

In this study, absence of suspicious ultrasound features was found to have a high negative predictive value of 0.94 (95\% CI 0.79-0.99), but presence of suspicious sonographic features was found to have a poor positive predictive value of 0.14 (95\% CI $0.03-0.36$ ) in cold nodules. In the population of nodules with no suspicious ultrasound findings, two were of malignant cytology (papillary carcinoma and mixed follicular and papillary carcinoma). One of these two nodules demonstrated dense peripheral rim calcification with posterior acoustic shadowing which obscured most of the lesion (Figures 5 and 6). There is controversy regarding the significance of macrocalcification or rim calcification as a sonographic sign predicting malignancy. While traditionally it has been reported as a sign of benignity, some studies report it may be seen in malignancy [14-16], particularly if there is disruption of peripheral calcification or if it is present in combination with other suspicious sonographic features [15,17]. If macrocalcification were included as a suspicious sonographic feature in our study, our data would reflect an even higher negative predictive value for thyroid ultrasound. Furthermore, the sensitivity and specificity is operator dependent and due to the retrospective nature of this study covering a relatively long time period, there was great variability in the sonographer experience and expertise performing the study. In recent practice at our institution we have instigated a thyroid nodule clinic which is run by a select few sonographers who demonstrate an interest in this field and we would expect even

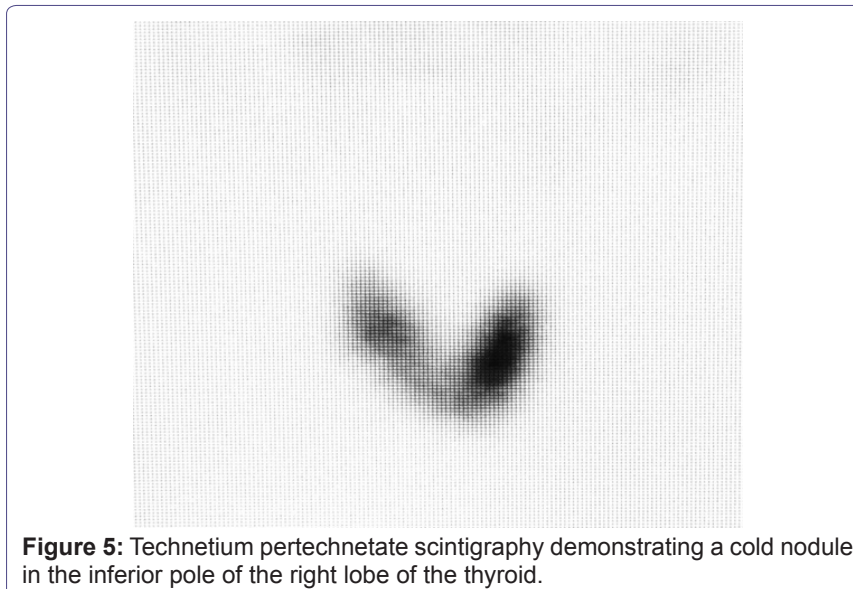
in the inferior pole of the right lobe of the thyroid.

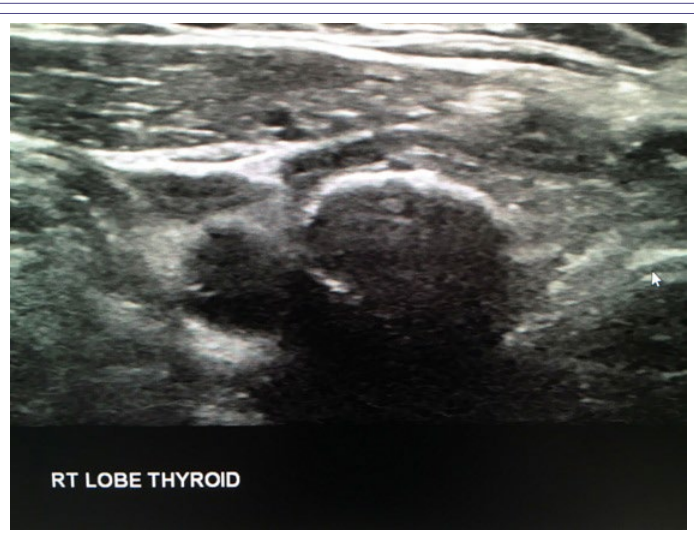

Figure 6: Ultrasound demonstrating a corresponding nodule with peripheral coarse calcification. Cytology revealed papillary thyroid cancer. 
correlation was found between other sonographic features and cytology. Rago and colleagues study of cold nodules in 1998 in the European population found no single ultrasound feature was significantly predictive of malignancy but a combination of patterns (particularly absence of halo and the presence of microcalcifications) was found to be highly predictive of malignancy (high specificity of $93 \%$ but low sensitivity of $36 \%$ ).

The overall poor positive predictive value [0.14 (95\% CI 0.03-0.36)] of suspicious sonographic features in determining malignancy in cold nodules is in contradistinction from Moon and colleagues multicenter data from the United States which found strong statistically significant correlations between sonographic features including taller than wide shape, spiculated margin, marked hypoechogenicity, microcalcification and macrocalcification with malignancy. The presence of at least one of these findings giving a sensitivity of $83 \%$ and specificity of $74 \%$.

The small sample size is a limitation of this study and up to a third of the nodules were excluded due to inadequate or indeterminate cytology. Other limitations include the assumption in our study that cytology is the gold standard which has in fact been shown to be open to interpretation error by the pathologist. False negative rates of less than $5 \%$ and false positive rates of $1 \%$ are quoted in experienced readers [10].

\section{Conclusion}

The rate of malignancy in cold nodules is low in the absence of suspicious ultrasound features. There was a statistically significant association between absence of suspicious sonographic findings and benign cytology in our study. This suggests that ultrasound can be used to stratify a cold thyroid nodule before invasive procedures are performed.

\section{Acknowledgement}

No declarations.

\section{References}

1. Tan GH, Gharib H (1997) Thyroid incidentalomas: management approaches to nonpalpable nodules discovered incidentally on thyroid imaging. Ann Intern Med 126: 226-231.

2. Mortensen JD, Woolner LB, Bennett WA (1955) Gross and microscopic findings in clinically normal thyroid glands. J Clin Endocrinol Metab 15: 12701280 .
3. Mazzaferri EL (1993) Management of a solitary thyroid nodule. N Engl J Med 328: 553-559.

4. Hegedus L (2004) Clinical practice. The thyroid nodule. N Engl J Med 351: 1764-1771.

5. Sarne D, Schneider AB (1996) External Radiation and Thyroid Neoplasia. Endocrinology \& Metabolism Clinics 25: 181-195.

6. Cappelli C, Castellano M, Pirola I, Cumetti D, Agosti B, et al. (2007) The predictive value of ultrasound findings in the management of thyroid nodules. QJM 100: 29-35.

7. Abdel-Razzak M, Christie JH (1997) Thyroid Carcinoma in an Autonomously Functioning Nodule. Journal of Nuclear Medicine 20: 1001-1002.

8. Rubenfeld S, Wheeler TM (1988) Thyroid cancer presenting as a hot thyroid nodule: report of a case and review of the literature. Thyroidology 1: 63-68.

9. Kountakis SE, Skoulas IG, Maillard AA (2004) The radiologic work-up in thyroid surgery: fine-needle biopsy versus scintigraphy and ultrasound. Ear Nose Throat J 81: 151-154.

10. Mackenzie, E Mortimer R (2004) Thyroid nodules and thyroid cancer. MJA 180: $242-247$.

11. Pellegriti G, Scollo C, Lumera G, Regalbuto C, Vigneri R, et al. (2004) Clinical behavior and outcome of papillary thyroid cancers smaller than $1.5 \mathrm{~cm}$ in diameter: study of 299 cases. J Clin Endocrinol Metab 89: 3713-3720.

12. Ito Y, Ubruno T, Nakano K, Takamura Y, Miya A, et al. (2003) An observation trial without surgical treatment in patients with papillary microcarcinoma of the thyroid. Thyroid 13: 381-387.

13. Rago T, Vitti P, Chiovato L, Mazzeo S, De Liperi A, et al. (1998) Role of conventional ultrasonography and color flow-doppler sonography in predicting malignancy in 'cold' thyroid nodules. Eur J Endocrinol 138: 41-46.

14. Takashima S, Fukuda H, Nomura N, Kishimoto H, Kim T, et al. (1995) Thyroid nodules: Re-evaluation with ultrasound. Journal of Clinical Ultrasound 23: $179-184$.

15. Kim MJ, Kim EK, Kwak JY, Park CS, Chung WY, et al. (2008) Differentiation of thyroid nodules with macrocalcifications: role of suspicious sonographic findings. J Ultrasound Med 27: 1179-1184.

16. Frates MC, Benson CB, Doubilet PM, Kunreuther E, Contreras M, et al. (2006) Prevalence and distribution of carcinoma in patients with solitary and multiple thyroid nodules on sonography. J Clin Endocrinol Metab 91: 34113417.

17. Moon WJ, Jung SL, Lee JH, Na DG, Baek JH, et al. (2008) Benign and malignant thyroid nodules: US differentiation--multicenter retrospective study. Radiology 247: 762-770. 